Scientific Journal of Silesian University of Technology. Series Transport Zeszyty Naukowe Politechniki Śląskiej. Seria Transport

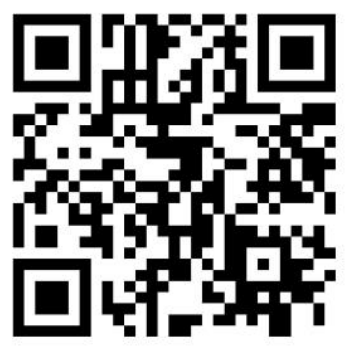

Volume 110

2021

p-ISSN: 0209-3324

e-ISSN: 2450-1549

DOI: https://doi.org/10.20858/sjsutst.2021.110.9

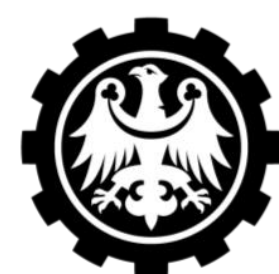

Silesian

University of Technology

Journal homepage: http://sjsutst.polsl.pl

Article citation information:

Maláková, S. Teeth deformation of non-circular gears. Scientific Journal of Silesian

University of Technology. Series Transport. 2021, 110, 105-114. ISSN: 0209-3324.

DOI: https://doi.org/10.20858/sjsutst.2021.110.9.

Silvia MALÁKOVÁ1

\title{
TEETH DEFORMATION OF NON-CIRCULAR GEARS
}

Summary. In practice, gear units whose transmission number is not constant during one revolution are used. Such gears include the proposed elliptical transmission. Its application can be (missing a word?) and the automotive industry. The gears set consists of a pair of identical elliptical gears. The transmission ratio of the designed elliptical gear is not constant. The basic kinematic characteristics of this transmission are described in this work. The deformation in contact point of non - circular gears is determined by the finite element method in this paper. The results are compared with the deformation of the teeth of the spur gears.

Keywords: non-circular gears, teeth deformation, FEM, spur gear

\section{INTRODUCTION}

Gears are a logical continuation of the invention of the wheel. That gears are called the biggest invention after the wheel is not unthinkable. More so, we cannot live a normal day in our lives without gears: without gears no production, no energy and no transport [4].

By the year 100 v.C., the Greeks used metal gears with cylindrical teeth in complex computing equipment and astronomical calendars. We know this by the discovery of the Antikythera Mechanism (Fig. 1), the oldest known gear machine. This ancient mechanism was found in 1900, in a wreck off the coast of the Greek island of Antikythera. It contains more than 30 gears for complicated astronomical calculations of time. Was this the first computer? In later

\footnotetext{
${ }^{1}$ Faculty of Mechanical Engineering, Technical University of Košice, Letná 9, 04200 Košice, Slovakia. Email: silvia.malakova@tuke.sk. ORCID: https://orcid.org/0000-0003-1660-6333
} 
centuries, the gear became one of the most important parts of modern technology, incorporated into almost all mechanisms, machines and vehicles.

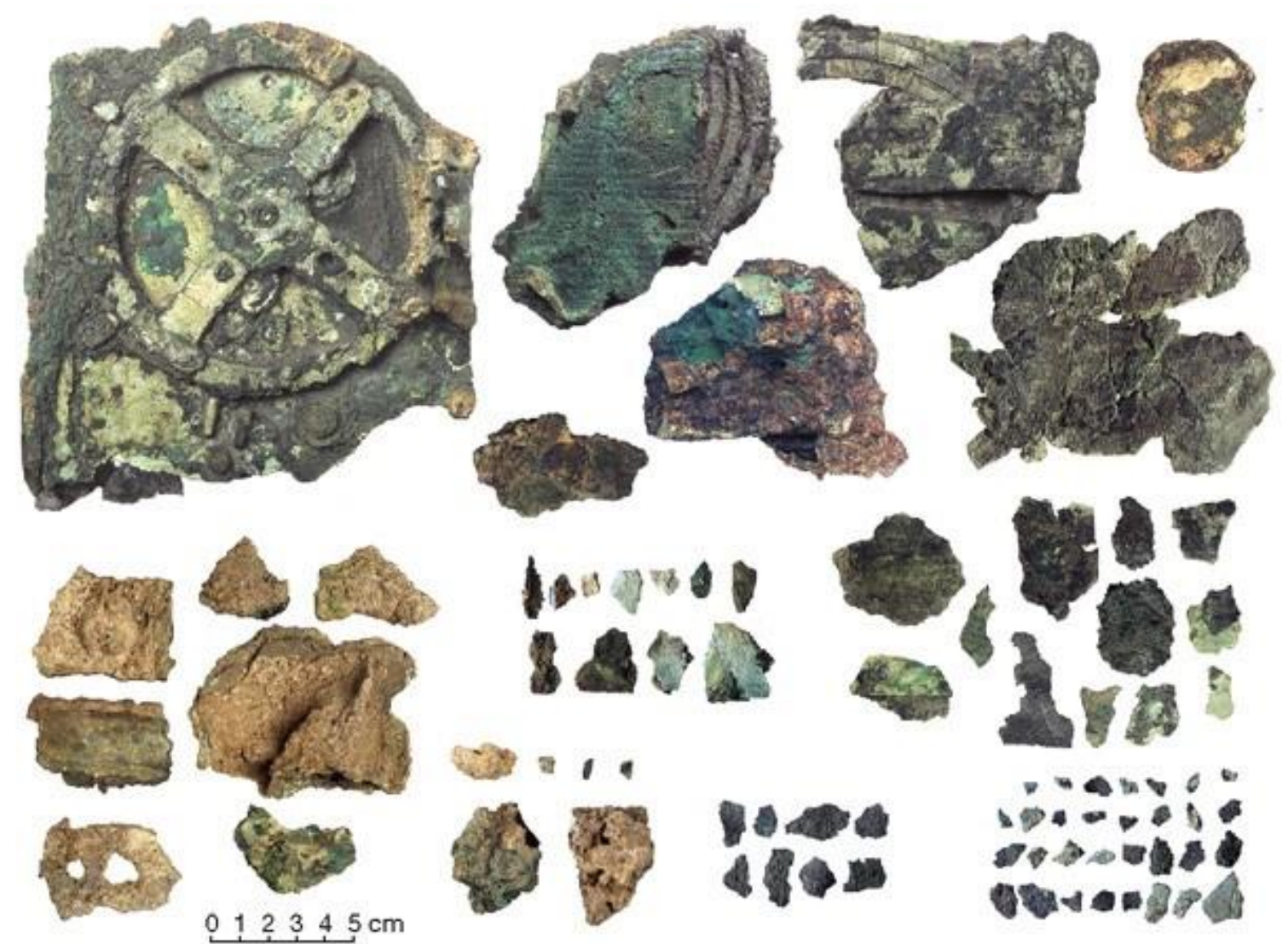

Fig. 1. Remains of the oldest gear machine (Antikythera Mechanism) [2]

"Standard" gearboxes are commonly used in practice. They are characterised by a constant gear ratio. This means that when the drive gear rotates, the driven gear also rotates evenly, so the gear ratio has to be constant during one revolution. The teeth of these "standard" gears have the same shape on one gear and the teeth profile is symmetrical or asymmetric in rare cases.

Special gears, including non-circular gears, are being increasingly used. The idea of noncircular gearboxes comes from the forerunners of engineering thinking [11]. In Richard of Wallingford's Horologium [23], we find the first known example of a non-circular wheel, which dates back to the 14th century. The tradition of using non-circular gears in clockwork has been followed by other clockmakers. For instance, Lorenzo Della Volpaja (1446-1512) made -towards the end of the 15th century, an astronomical planetary clock, for the City of Florence [1]. Non-circular gears from Leonardo da Vinci's sketches are also known [24].

Non-circular gears are among gears with a variable transmission ratio. Examples of the use of non-circular gears in practice include, for example, mechanical presses, for optimisation of work cycle kinematics [14,26]; forging machines, for optimising the work cycle parameters; high torque hydraulic engines for bulkhead drives; textile industry machines, for improving machine kinematics resulting in the process optimisation and application in oval gear flowmeters. There is non-circular transmission usually used to provide a periodically variable ratio. 
In this paper, the kinematic properties for the proposed elliptical gear set are presented. It is a model of a non-standard eccentric elliptical transmission with a continuously changing gear ratio for specific parameters. The deformation in contact point of non - circular gears is determined by the finite element method in this paper. The results are compared with the deformation of the teeth of the spur gears.

One should not forget about the possibility of diagnosing damages with the use of vibroacoustic diagnostics $[2,3,5,6,12,17]$.

\section{INVESTIGATED ELLIPTICAL GEARS SET}

To sponsor the work of the private sector has been created using the CAD model of gear with variable transmission in the range $u=0.5$ to 2.0 , with the number of teeth $z_{1}=z_{2}=24$ and gearing module $m_{n}=3.75 \mathrm{~mm}$, the axial distance $a=90 \mathrm{~mm}$ and for a one sense of rotation (Fig. 2). The transmission ratio of the designed elliptical gear is not constant. It varies continuously from 0.5 through 1.0 to 2.0 and back (Fig. 3). In this way, the transmission ratio changes during one revolution. For fast transmission, the value of the conversion number is less than 1.0. For slow transmission, the value of the conversion number is greater than 1.0. The gears set consists of a pair of identical elliptical gears. The centre of rotation is in one of the foci of the pitch ellipse, that is, they are eccentrically mounted gears [16]. Each of the twelve teeth of the gear is different, the other twelve teeth of the same wheel are the same. The lateral curve is involute and is different for the active and passive side of the tooth. These are gears with an asymmetrical tooth profile.

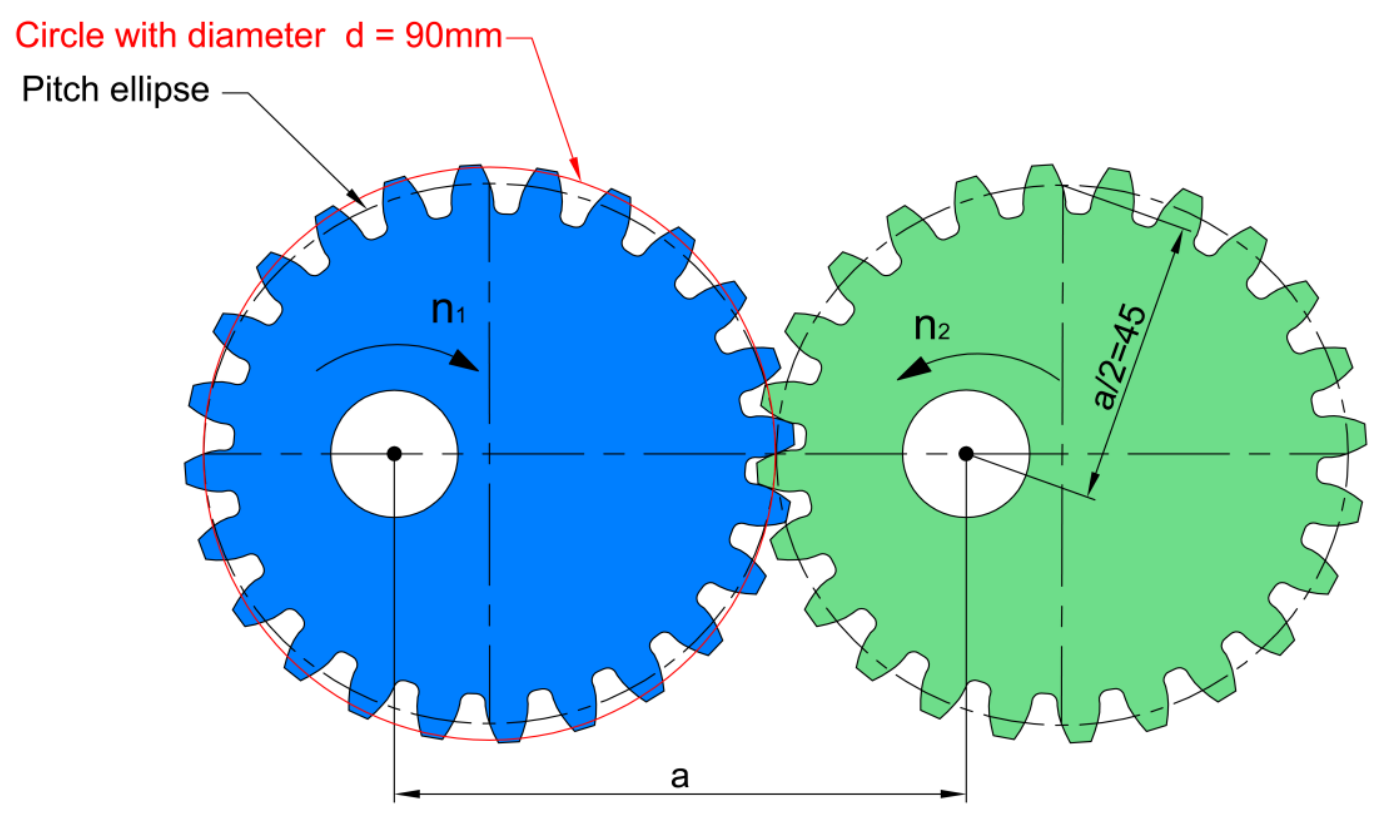

Fig. 2. Designed elliptical gears set

In pursuit of kinematic ratios on the proposed gearings, we assume from the right mesh conditions. Kinematic conditions were processed for the gear 1 (the centre of rotation at point $\mathrm{O}_{1}$ ) and the gear 2 (with the centre of rotation at point $\mathrm{O}_{2}$ ). The two gears are shown in a kinematic dependence one graph (on the horizontal axis of the wheel teeth first). The angular 
velocity on the drive wheel gear and the driven wheel gear is constant for standard spur gears. For designed elliptical gearing with variable transmission ratio, the angular velocity of the driven wheel is not constant but is changed according to the continuous changing of the gear ratio. This is shown in Fig. 4, the angular velocity is constant for the drive elliptical wheel $\left(\omega_{1}=100 \mathrm{~s}^{-1}\right)$ and the driven elliptical wheel is not constant $\left(\omega_{2 \mathrm{i}}\right)$.

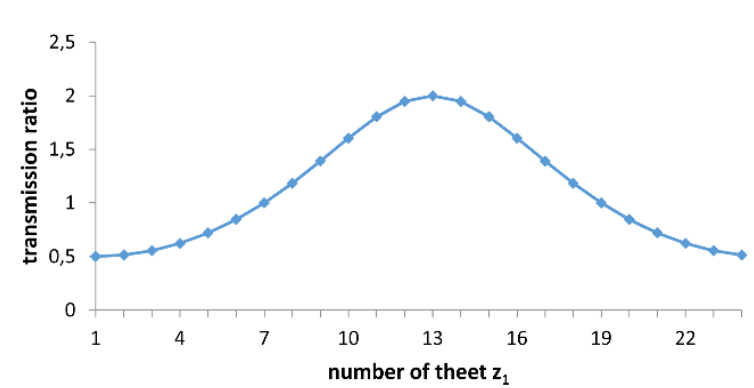

Fig. 3. Changing the transmission ratio

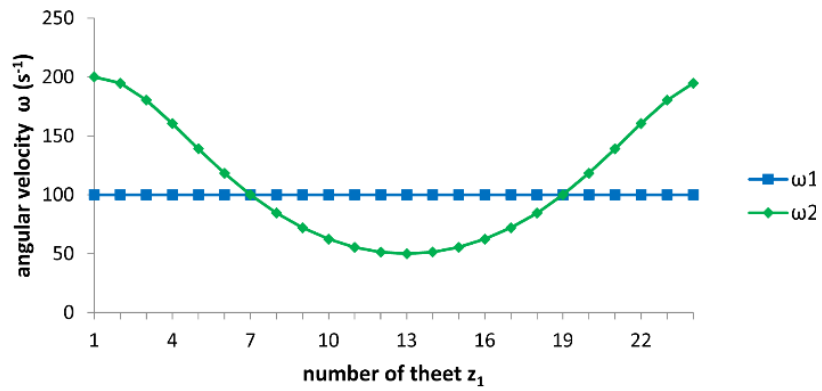

Fig. 4. The angular velocity

Real of load gear teeth with variable gear ratio is not constant. By way of illustration is given unit input torque (driven) spur gear $M_{k l}=100 \mathrm{Nm}$. Fig. 5 shows the course of torque $M_{k l}$ on the input gear and torque $M_{k 2}$ on the output (driven) gear $\left(M_{k 2 i}=M_{k 1} \cdot u_{i}\right)$, where $u$ is transmission ratio. In Fig. 6 are the value of changing tangential tooth load the driver and driven gear $F_{01}=$ $F_{02}\left(F_{01}=M_{k 1} / r_{1 i}\right)$, where $r_{1 i}$ is the radius of mesh points for the driver gear wheel and the radial force $F_{r 1}=F_{r 2}\left(F r_{1}=F_{01} \cdot \operatorname{tg} \alpha\right)$ and the resultant force acting on the side of the tooth $F_{N 1}=F_{N 2}$ $\left(F_{N 1}=F_{01} / \cos \alpha\right)$, where $\alpha$ is a pressure angle is $20^{\circ}$.

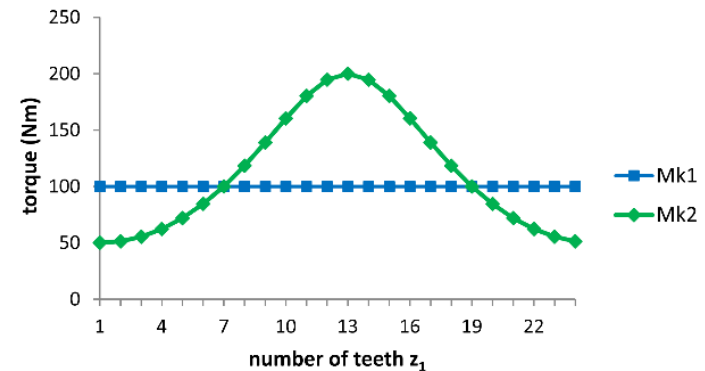

Fig. 5. The course of torque

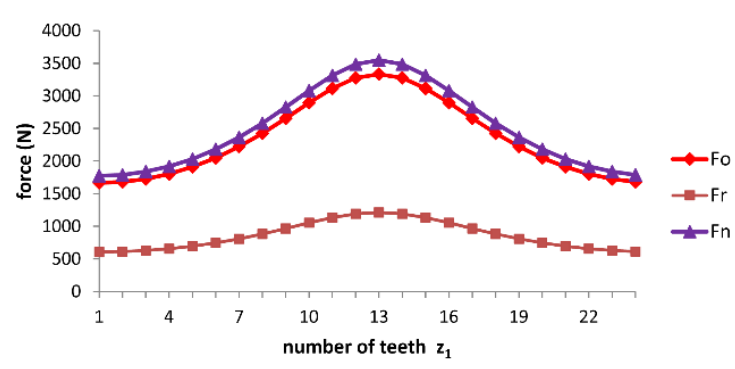

Fig. 6. The course of force

\section{TEETH DEFORMATION OF DESIGNED NON-CIRCULAR GEAR SET}

Knowledge of the deformation properties of gearing is very important. Consider first the one tooth (Fig. 7a). Action of the resulting normal force $F$ is deformed tooth. This is shown in the figure by a thin line. The resultant deformation in the direction of action of the normal force $\delta_{\mathrm{i}}$ ( $i=1,2$ - index that distinguishes whether it is a tooth of the pinion-drive wheel or driven wheel tooth) consists of a deflection bending, shear, deformation in the area of constraint and the touch deformation $[7,15,20]$.

It is necessary to determine the deformation meshing teeth, that is, deformation of teeth pair that you can imagine and illustrate two ways (Fig.7b,c). Figure $7 \mathrm{~b}$ shows a pair of teeth that in non-loaded aspect are contact at point $X$ on the line of contact $\tau_{B}$. The profiles meshing teeth are deformed after loading. The deformed teeth profiles intersect the line of contact at points $X_{1}$ 
and $X_{2}$. We can then determine the total deformation of the pair of teeth as the sum of the deformation of both teeth $\delta_{1}$ and $\delta_{2}$. Figure 8c shows a pair of teeth that in non-loaded aspect are contact at point $X^{\prime}$ on the line of contact $\tau_{B}$. The deformed teeth profiles intersect the line of contact at points $X_{1}$ and $X_{2}$, because one of wheel gears is fixated (restrained). The total deformation of one pair of meshing teeth determined by equation (1).

$$
\delta=\delta_{1}+\delta_{2}=\left|\varphi_{\delta 1} \cdot r_{b 1}\right|+\left|\varphi_{\delta 2} \cdot r_{b 2}\right|=\left|\varphi_{\delta}^{1} \cdot r_{b 1}\right|
$$

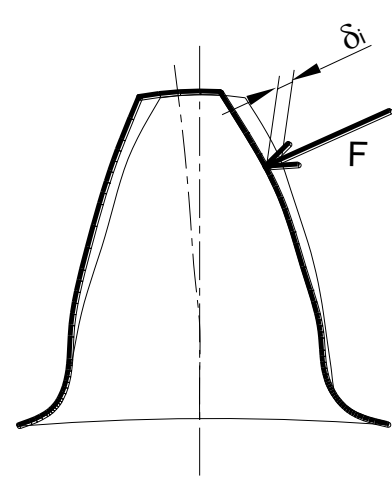

a)

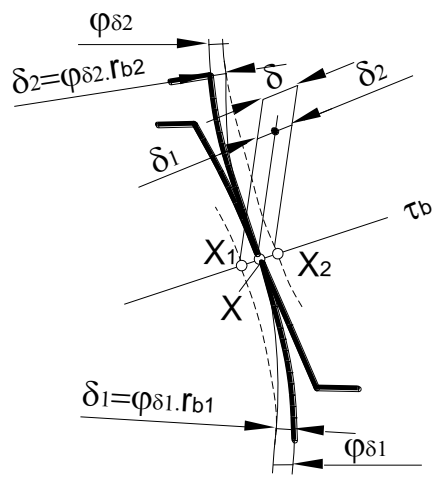

b)

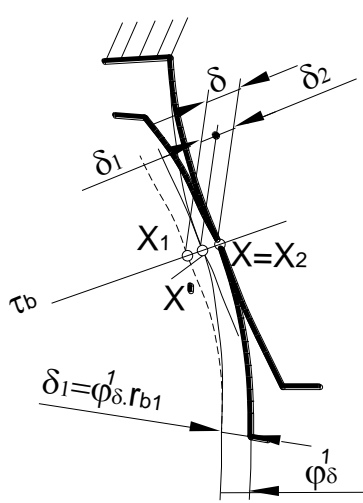

c)

Fig. 7. a) The deformation of the tooth, b)-c) deformation of a one pair of spur gear teeth [21]

Due to the complex shape of the teeth, the theoretical determination of tooth deformation is difficult. A lot of work is devoted to this issue. The initial assumption is usually a strongly idealised idea of the linear dependence of the tooth deflection on the load and the tooth is considered to be a beam stressed by bending $[8,13]$. The question of the exact determination of the deformation of the teeth remains unresolved at the required level; therefore, the experimentally determined values are usually used.

Recently, with the ever-evolving computational technology, which performs extensive calculations, we increasingly come across modern numerical methods for solving a wide range of gear problems in the available literature. These methods include the finite element method [25]. This method belongs to the numerical methods of mathematics, it is widely used for solving problems of elasticity and strength, dynamics of flexible bodies, heat transfer and many other engineering problems [18]. In this paper, the deformation of the designed gearing is solved using the finite element method (FEM).

When solving the requirements for the accuracy of the calculation of technical problems using the finite element method, the basic problem of solving the deformation analysis of the gearing of the examined gear lies in the choice of the solved area of the gear wheel [10,27]. It is not expedient to calculate the gears as a whole by the finite element method, but only as a part of the gear $[19,22]$.

Since it is a gear set with a time-varying transmission ratio, the transmission ratio of which ranges from 0.5 to 1 to 2 , the deformation of those teeth engaged when the transmission ratio 0.5 is examined; 1 and 2 . The assumed segments of the investigated elliptical gear are shown in Fig. 8, assuming that, similarly to "standard" spur gears with straight teeth, it is not expedient to calculate the deformation of teeth using FEM on the whole wheel model, but only parts segment. 


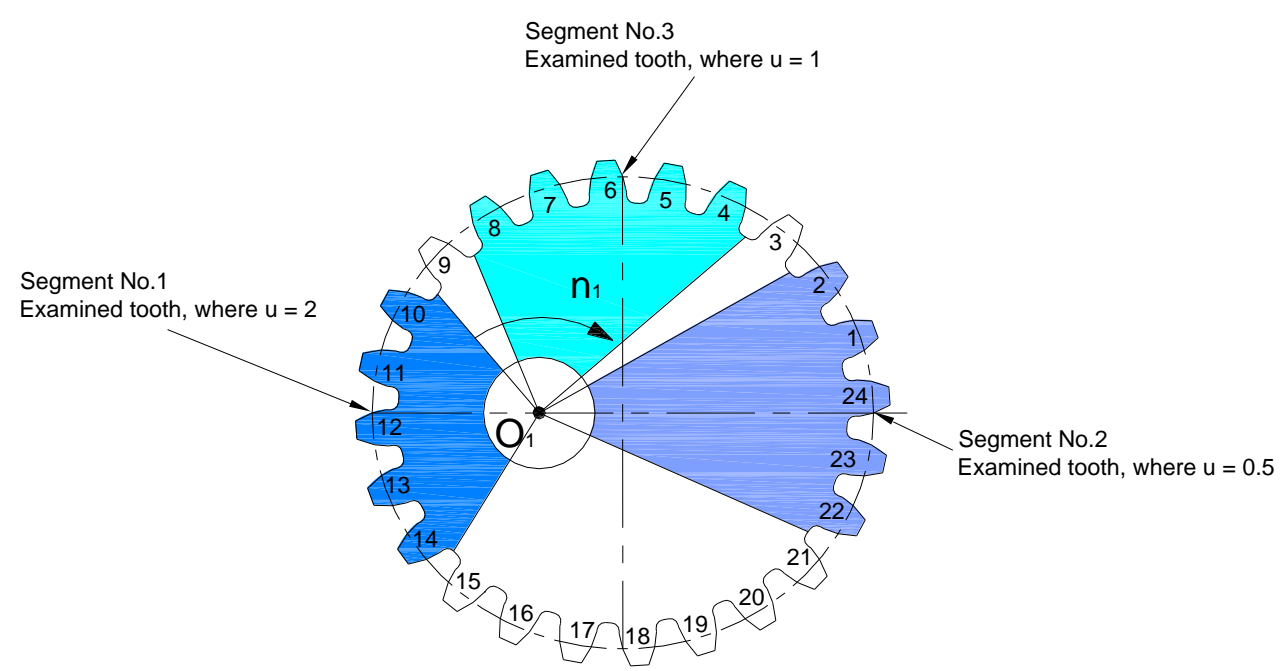

Fig. 8. Drive wheel segments

To determine the deformation of gearing under load, it is necessary to know the apportionment of the load on each gearing pairs with two pairs meshing. In the beginning, let us consider with the simplest, ideal load apportionment when on two pairs meshing is the load divided by half for each couple of teeth in the meshing (Fig. 9). Points $A, B, \mathrm{C}, D, E$ are the characteristic points of the meshing for spur gears.

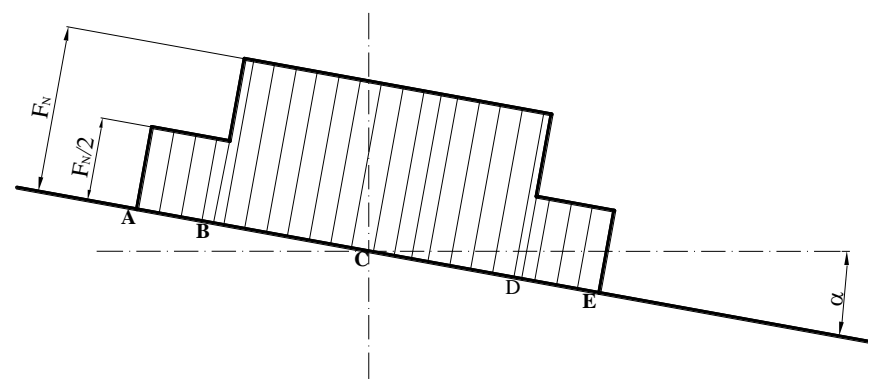

Fig. 9. Load distribution on the line of contact

To determine the computer model for the studies of deformation of the teeth using FEM, it was necessary to determine material constants, define the type of the finite element, and to select appropriate boundary conditions (geometry and power).

The course of the deformation of the toothing in the designed elliptical eccentrically mounted gear set, if during the whole engagement we observe the tooth of the drive wheel, which together with the engaging tooth reaches the transmission number 1, is shown in Figure 10, (the force $F_{N}=1000[\mathrm{~N}]$ ). In this figure, is the progress of the overall deformation of teeth solved by FEM for the spur gears, in the teeth, which in the meshing reaching gear ratio 1 and for the division of load by Fig. 9. Deformation of pairs of teeth over the meshing along the length of meshing line changes. Maximum value of deformation shall, in this case, be the endpoints lonely meshing (if we consider the image-pair) and the minimum value shall also meshing in two pairs of endpoints lonely meshing. The points B and D, which is the solitary meshing points, leads to a step change deformation teeth and it will input the next couple teeth to meshing. 


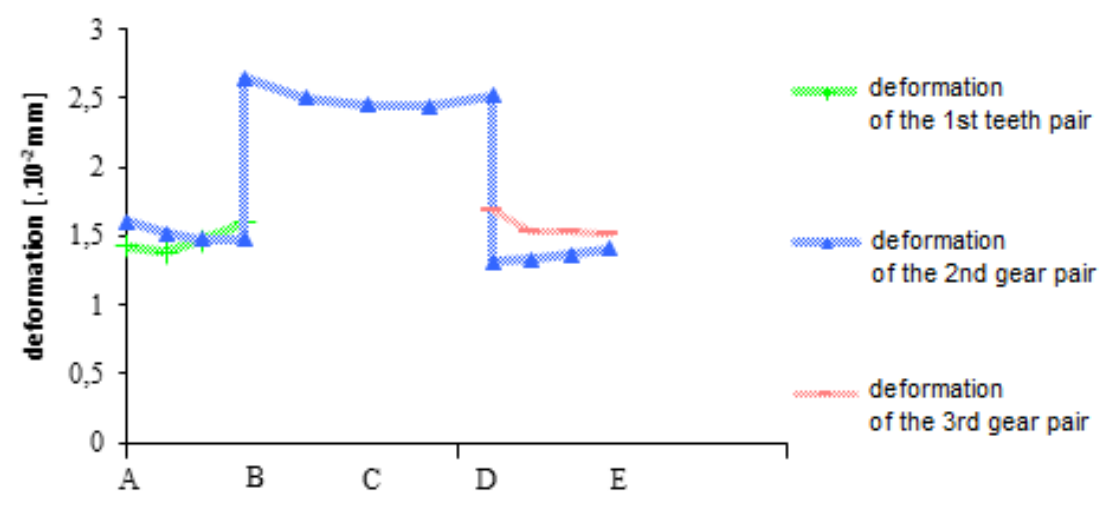

Fig. 10. Course of tooth deformation for elliptical gear set

To determine the resulting deformation of the teeth, it is necessary to determine the deformation of individual pairs. Figure 11 shows the progress of the overall deformation of teeth solved by FEM for the spur gears with number of teeth $z_{1,2}=24$, the module of teeth $m=3,75[\mathrm{~mm}]$, the force $F_{N}=1000[\mathrm{~N}]$ and width of gearing $b_{1,2}=10[\mathrm{~mm}]$, which in the meshing reaching gear ratio 1 and for the ideal division of load. Deformation of pairs of teeth over the meshing along the length of meshing line changes. Maximum value of deformation shall, in this case, be the endpoints lonely meshing (if we consider the image-pair) and the minimum value shall meshing in two pairs of endpoints lonely meshing as well. The points B and D, which is the solitary meshing points, leads to a step change deformation teeth and it will input the next couple of teeth to meshing.



Fig. 11. Course of tooth deformation for spur gear set

The difference during the deformation in the designed gearing and the standard ring spur gear (Fig. 12) results from the smooth change of the gear number, thus, the change of the force acting on the individual teeth, the teeth being loaded with different resulting normal forces. Another difference results from the different length of the engagement line and the related engagement duration factor, which acquires smaller values for the designed elliptical gears than for comparable spur gears. 


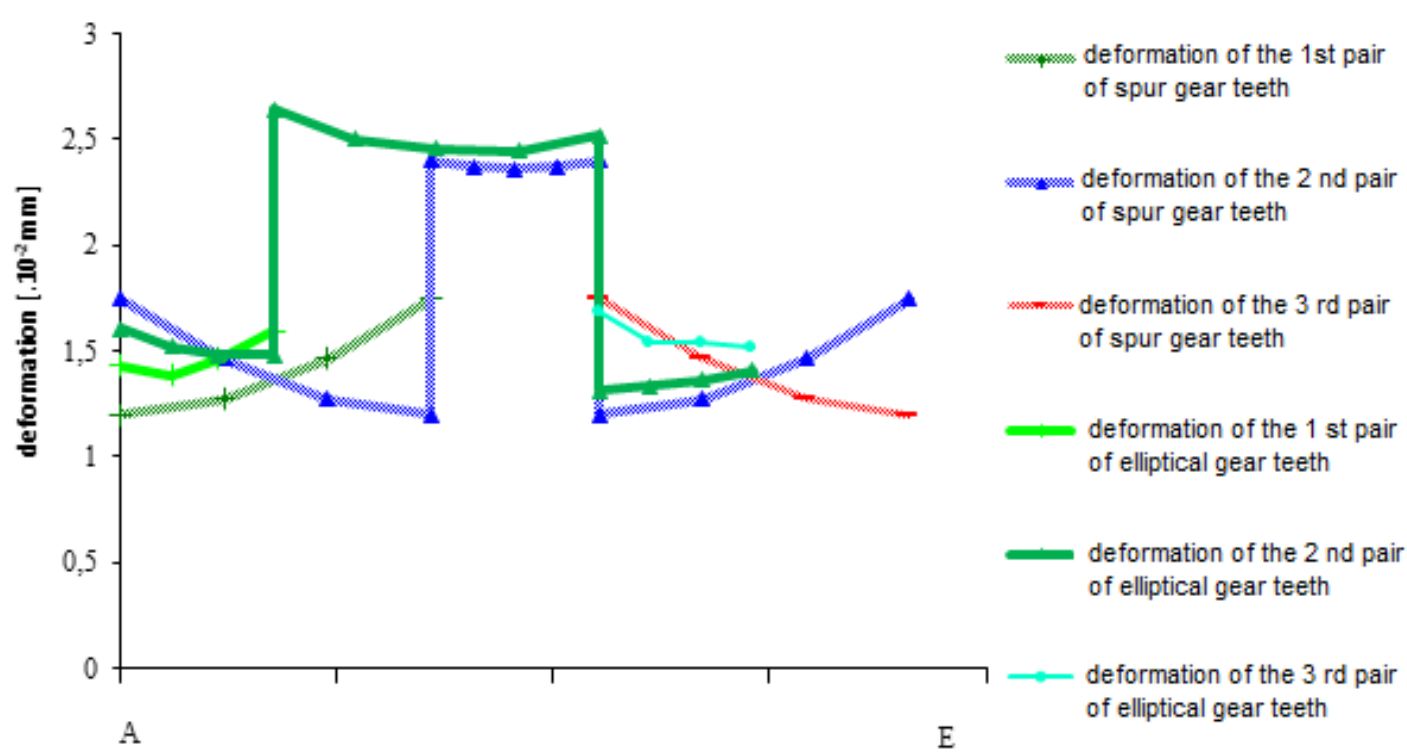

Fig. 12. Deformation comparison

\section{CONCLUSION}

The gearing with changing transmission gear ratio is used in the practice, even though the "standard" gearing with constant transmission gear ratio is usually used. In practice, we also encounter non-circular gears. In this paper, an elliptical gear set designed for specific parameters is presented. It is the gearing with variable transmission.

The angular velocity on the drive wheel gear and the driven wheel gear is constant for standard spur gears. For designed elliptical gearing with variable transmission ratio, the angular velocity of the driven wheel is not constant but is changed according to the continuous changing of the gear ratio. Real of load gear teeth with variable gear ratio is not constant.

Deformation of pairs of teeth over the meshing along the length of meshing line changes. Maximum value of deformation shall, in this case, be the endpoints lonely meshing (if we consider the image-pair) and the minimum value shall also be meshing in two pairs of endpoints lonely meshing. The difference during the deformation in the designed gearing and the standard ring spur gear results from the smooth change of the gear number, thus, the change of the force acting on the individual teeth, the teeth being loaded with different resulting normal forces. The deformation of the designed elliptical eccentrically mounted gear differs from the stiffness of the standard spur gearing.

\section{Acknowledgement}

This paper was written within the framework of Grant project "VEGA 1/0290/18 Development of new methods of determination of strain and stress fields in mechanical system elements by optical methods of experimental mechanics" and "KEGA 041TUKE-4/2017Implementation of new technologies specified for solution of questions concerning emissions of vehicles and transformation of them into the educational process in order to improve quality of education" and "VEGA 1/0528/20 - Solution of new elements for mechanical system tuning". 


\section{References}

1. Addomine M., et al. 2018. „A landmark in the history of non-circular gears design: The mechanical masterpiece of Dondi's astrarium“. Mechanism and Machine Theory 122: 219-232.

2. Berlato Francesco, Gianluca D’elia, Mattia Battarra, Giorgio Dalpiaz. 2020. „Condition monitoring indicators for pitting detection in planetary gear units“. Diagnostyka 21(1): 3-10.

3. Chen Dingke, Changbin Mao, Bin Qin. 2020. „Study on transformer fault diagnosis technology of VMD local signal de-noising based on kurtosis - approximate entropy“. Diagnostyka 21(1): 81-87.

4. Chen Y.Z., H. Huang. 2016. „A variable-ratio line gear mechanism“. Mechanism and Machine Theory 98: 151-163.

5. Czech Piotr. 2013. „Diagnosing a car engine fuel injectors' damage”. Communications in Computer and Information Science 395: 243-250.

DOI: https://doi.org/10.1007/978-3-642-41647-7_30. Springer, Berlin, Heidelberg. ISBN: 978-3-642-41646-0; 978-3-642-41647-7. ISSN: 1865-0929. In: Mikulski Jerzy (eds), Activities of transport telematics, 13th International Conference on Transport Systems Telematics, Katowice Ustron, Poland, October 23-26, 2013.

6. Czech Piotr. 2013. „Intelligent Approach to Valve Clearance Diagnostic in Cars”. Communications in Computer and Information Science 395: 384-391. DOI: https://doi.org/10.1007/978-3-642-41647-7_47. Springer, Berlin, Heidelberg. ISBN: 978-3-642-41646-0; 978-3-642-41647-7. ISSN: 1865-0929. In: Mikulski Jerzy (eds), Activities of transport telematics, 13th International Conference on Transport Systems Telematics, Katowice Ustron, Poland, October 23-26, 2013.

7. Fattahi A.M., M.Gh. Khosroshah. 2017. „Three Dimensional Stress Analysis of a Helical Gear Drive with Finite Element Method“. Mechanika 23(5): 630-638.

8. Figlus Tomasz. 2019. „A Method for Diagnosing Gearboxes of Means of Transport Using Multi-Stage Filtering and Entropy". Entropy 21(5): 1-13.

DOI: $10.3390 / \mathrm{e} 21050441$.

9. Freeth T., et al. 2006. „Decoding the ancient Greek astronomical calculator known as the Antikythera Mechanism“. Nature 444(7119): 587-91. DOI: 10.1038/nature05357.

10. Grega Robert, et al. 2017. „Failure analysis of driveshaft of truck body caused by vibrations". Engineering Failure Analysis 79: 208-215. ISSN: 1350-6307.

11. Kapelevich Alexander. 2000. „Geometry and design of involute spur gears with asymmetric teeth". Mechanism and Machine Theory 35(1): 117-130.

12. Kluczyk Marcin, Andrzej Grządziela. 2020. „Detection of changes in the opening pressure of marine engine injectors using vibration methods“. Nase More 67(1): 1-8. ISSN: 0469-6255. DOI: 10.17818/NM/2020/1.1.

13. Kul'ka J. et al. 2018. "Failure analysis of the foundry crane to increase its working parameters". Engineering Failure Analysis 88: 25-34.

14. Murčinková Z., K. Vasilko. 2017. "The proposal how to make the basic machining technologies - turning, milling, planing - more productive." Manufacturing Technology 17(2): 261-266. ISSN: 1213-2489.

15. Neusser Zdenek, Tomas Vampola, Michael Valasek. 2017. „Analytical gear mesh model using 3D gear geometry“. Mechanika 23(3): 425-431.

16. Pacana Jacek, et al. 2015. „Improvement of the gear production process by automating their strength calculations". Acta Mechanica Slovaca 19(4): 22-25. ISSN: 1335-2393. 
17. Pawlik Pawel. 2019. „,The diagnostic method of rolling bearing in planetary gearbox operating at variable load“. Diagnostyka 20(3): 69-77.

18. Randall R.B., D.W. Kelly. 1998. „Modelling of spur gear mesh stiffness and static transmission error". Proceeding of the Institution of Mechanical Engine 1: 1-12.

19. Rincon Femandez, Fernando Viadero, 2013. „A model for the study of meshing stiffness in spur gear transmissions". Mechanism and Machine Theory 61: 30-58.

20. Šalamoun Č., I. Suchý. 1990. Čelní a šroubová soukolí s evolventním ozubením. SNTL, Praha, p. 466. [In Czech: Spur and helical gears with involute gearing].

21. Shimanovsky Alexandr, et al. 2016. „Simulation of spur gear for their nonparallel axes". Acta Mechanica Slovaca 20(1): 28-32. DOI: 10.21496/ams.2016.005.

22. Tong S.-H., D.C.H. Yang. 1998. „Generation of identical noncircular pitch curves”. Journal of Mechanical Design 120: 337-341.

23. Turner J.A. 1975. „The tragical history of giovanni de dondi“. J. History Astron 6: 126-131.

24. Walter Isaacson. 2017. Leonardo da Vinci. Simon \& Schuster. ISBN: 1-4744-6676-7. $599 \mathrm{p}$.

25. Wojnar Grzegorz, Michał Juzek. 2018. „The impact of non-parallelism of toothed gear shafts axes and method of gear fixing on gearbox components vibrations numerical“". Acta Mechanica et Automatica 12(2): 165-171.

26. Zarebski Igor, Tadeusz Salacinski. 2008. „Designing of non-circulas gears“. The Archive of Mechanical Engineering LV(3): 275-292.

27. Zhang Xin, Shouwen Fan. 2016. „Synthesis of the steepest rotation pitch curve design for noncircular gear". Mechanism and Machine Theory 102: 16-35. DOI: 10.1016/j.mechmachtheory.2016.03.020.

Received 14.07.2020; accepted in revised form 03.11.2020

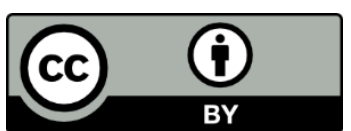

Scientific Journal of Silesian University of Technology. Series Transport is licensed under a Creative Commons Attribution 4.0 International License 